\title{
Pre Eclampsia and Iron Status: A Review
}

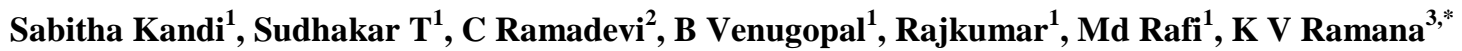 \\ ${ }^{1}$ Department of Biochemistry, Chalmeda AnandRao Institute of Medical Sciences, Bommakal, Karimnagar, Andhra Pradesh \\ ${ }^{2}$ Department of Obsterics and Gynaecology, Chalmeda AnandRao Institute of Medical Sciences, Bommakal, Karimnagar, Andhra Pradesh \\ ${ }^{3}$ Department of Microbiology, Prathima institute of Medical Sciences, Nagnur, Karimnagar, Andhra Pradesh \\ *Corresponding author: tejaswani19@gmail.com
}

Received May 30, 2014; Revised December 15, 2014; Accepted December 22, 2014

\begin{abstract}
Preeclampsia is an idiopathic multisystem disorder specific to pregnancy and development of hypertension and proteinuria, increased vascular resistance and endothelial dysfunction in the mother, altered placental perfusion and restricted fetal growth. The vasospasm leads to destruction of RBCs release iron thus, there is elevated serum iron levels in preeclamptic women. The excess iron released from destruction of RBCs can react with free radicals produced from cell membrane (as it is rich in polyunsaturated fatty acids) and circulating lipoproteins initiates lipid peroxidation both in placenta and vasculature. This is one of the significant etiologic factors in the endothelial cell damage of preeclampsia. the raised serum iron levels in turn alters the iron related parameters like total iron binding capacity(TIBC), serum ferritin, transferrin, percent saturation.
\end{abstract}

Keywords: preeclampsia, serum iron levels, TIBC, transferrin

Cite This Article: Sabitha Kandi, Sudhakar T, C Ramadevi, B Venugopal1, Rajkumar, Md Rafi, and K V Ramana, "Pre Eclampsia and Iron Status: A Review." American Journal of Medical and Biological Research, vol. 2, no. 6 (2014): 121-123. doi: 10.12691/ajmbr-2-6-1.

\section{Introduction}

When tissues become ischemic, reactive oxygen species (ROS) such as superoxide and hydrogen peroxide are produced, but these ROS may not be able to initiate any cellular damage directly. The transition metal ions such as iron, arising from ischemic placenta by destruction of red blood cells from thrombotic, necrotic and hemorrhagic areas can generate highly reactive hydroxyl radical by Fenton reaction. This radical can initiate lipid peroxidation which if uncontrolled results in endothelial cell damage $[1,2]$.

$\mathrm{Fe}^{+2}+\mathrm{H}_{2} \mathrm{O}_{2} \rightarrow \mathrm{Fe}^{+3}+\mathrm{OH}+\mathrm{OH}^{-}$(Fenton reaction)

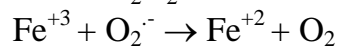

$\mathrm{O}_{2}{ }^{-}+\mathrm{H}_{2} \mathrm{O}_{2} \rightarrow \mathrm{O}_{2}+\mathrm{OH}^{-}+\mathrm{OH}^{-}$(HABER-WEISS REACTION)

\section{Iron Metabolism}

A very small quantity of iron is present in most of the cells of the body, in plasma and in other extra cellular fluids. The body conserves iron supply, so that less than $0.1 \%$ of the body iron is lost daily, mostly in desquamated cells $[3,4]$. The iron exist in two oxidised states ferric $(\mathrm{Fe}+3)$ and ferrous $(\mathrm{Fe}+2)$ ionic forms. The mucosal cells take up ferric form of iron during its absorption. The iron $(\mathrm{Fe}+3 / \mathrm{Fe}+2)$ act as cofactor for many biochemical activities of the cell.

Ferritin is the storage form of iron. Free iron acts as prooxidant agent and it is released from ferritin by the reducing agents that convert $\mathrm{Fe}+3$ into $\mathrm{Fe}+2$. Under stress or pathological conditions, it undergoes Fenton reaction and Haber - Weiss reaction to generate ROS, which in turn damage the biological macro molecules. Transferrin, the iron transfer protein may also undergo glycation due to stress or pathological conditions causing increased free iron levels. Glycated transferrin also enhances the production of free oxygen radicals such as hydroxide which amplify the oxidative effects of iron [5]. The iron levels of blood can be measured as serum Iron, Serum Total Iron Binding Capacity(TIBC), \% Transferrin saturation, UIBC, Serum Ceruloplasmin, Serum Ferritin.

\subsection{Total Iron Binding Capacity (TIBC)}

It measures the maximum amount of iron that serum proteins can bind and therefore is an indirect way of assessing transferrin levels.

Increased TIBC levels are seen in

- Iron deficiency anaemia

- Acute viral hepatitis

Decreased TIBC levels are seen in

- Liver elated inflammation, neoplasia and chronic diseases

- Severe malnutrition

- Renal \& Gastrointestinal diseases [6,7].

\subsection{Unsaturated Iron Binding Capacity (UIBC)}

It denotes the amount of transferrin unbound to iron. It is $2 / 3 \mathrm{rd}$ of TIBC [7].

$$
\mathrm{TIBC}=\mathrm{UIBC}+\mathrm{S} . \text { IRON }
$$

\subsection{Transferrin Saturation}


The percent of saturation of transferrin is calculated by S. Iron and S. TIBC by the formula [7].

\section{$\%$ Saturation of Transferrin $=$ S.Iron $/$ TIBC X 100}

- The percent saturation of transferrin levels helps to differentiate iron deficiency anaemia from iron overload.

The percentsaturation of transferrin

$<20 \%$ - Iron deficiency anaemia

The percentsaturation oftransferrin

$>50 \%$ - Iron overloadstatus

\subsection{Serum Ferritin}

It is iron storage protein containing 24 subunits and each ferritin can store about 4,500 iron(Fe+3) atoms. Ferritin participates in ferroxidase activity, iron binding, oxido reductase activity, metal ion binding $[8,9]$.

- Decreased Ferritin - Anaemia

- Increased Ferritin - Severe malnutrition, iron overload disorders.

\subsection{Ceruloplasmin Having Ferroxidase Activity}

Ceruloplasmin $(\mathrm{CP})$ is a copper containing protein seen in serum. The primary physiological role of $\mathrm{CP}$ is its action in plasma redox reactions. It can act as oxidant or antioxidant depending on factors such as free ferric ions and ferritin binding sites. It plays an important role in oxidation of $\mathrm{Fe}+3$ to $\mathrm{Fe}+2$ and vice versa. It thus permits incorporation of iron into transferrin without forming toxic iron products.

CP under physiological conditions controls lipid peroxidation (by direct oxidation of cations). But in the presence of superoxide, CP is a major contributor to Low Density Lipoprotein (LDL) oxidation [10,11].

$\mathrm{CP}$ levels are increased in

*Menke's disease

- Wilsons disease

- Copper deficiency

$\mathrm{CP}$ levels are seen in

- Pregnancy

- Acute \& Chronic inflammation

- Lymphoma

\section{Preeclampsia and Iron Levels}

An imbalance between pro -oxidants and anti -oxidants results in oxidative stress which increases the potential for the development of pre eclampsia [12]. There is raised serum iron, percent transferrin saturation, serum ferritin and decreased TIBC, UIBC and serum transferrin and ceruloplasmin levels in preeclamptic women compared to the normal healthy pregnant controls.

The elevated serum iron levels are due to hemolysis caused by physical destruction of RBC as a result of vasospam or abnormal endothelial cell erythrocyte interactions. Excess iron is a causative factor of oxidative stress (i.e., in its radical form) involved in the pathogenesis of pre eclampsia [13,14]. The excess iron released from destruction of RBCs can react with free radicals produced from cell membrane (as it is rich in polyunsaturated fattyacids) and circulating lipoproteins initiates lipid peroxidation [15]. In addition to this the damaged placenta is a site for release of free radicals(FR) in pre eclampsia. The elevation or excess iron can also react with these released FR of placenta and can initiate and propagate lipid peroxidation both in placenta and vasculature. This is one of the significant etiologic factor in the endothelial cell damage of pre eclampsia [16]. The doubling of percent transferrin saturation is due to raised serum iron and decreased serum transferrin levels. Even at low concentrations iron components such as hemoglobin and heme can increase LDL oxidation, suggesting a role of iron in LDL oxidation of preeclampsia [17].

The decreased TIBC correlates well with decreased s. Transferrin levels. This effect can cause increased proliferation of bacteria in blood due to excessive availability of free iron, and it also causes increased production of hydroxyl radicals in the tissues. The reduced transferrin levels also leads to proteinuria in pre eclampsia [18]. The decreased UIBC contributes to release of iron free radicals from ischemic placenta in pre eclampsia. The decreased UIBC, S. Transferrin levels suggests a role of iron in the development of endothelial dysfunction seen in pre eclampsia [19].

The increased ferritin levels of serum in pre eclampsia women are thought to be due to hepatic damage, resulting in leakage of ferritin into circulation [20]. James M Roberta et al. quoted that serum ferritin increase in pre eclampsia as a marker of acute phase reaction. Because inflammatory responses are increased in preeclampsia, these results in alterations in iron homeostasis [21]. The hyper ferritinemia seen in pre eclampsia is due to hepatic cell damage and increased ferritin synthesis by placenta. Thus, hepatocellular damage is the likely reason for the increase in ferritin levels of women with pre eclampsia [22].

The decreased ceruloplasmin levels seen in pre eclampsia indicate reduced ferroxidase activity. The raised serum ferritin and reduced ceruloplasmin levels suggest the intensification of free radical oxidation, results in disturbance of anti oxidant defense. The enzymatic function of Ceruloplasmin and transferrin contributes to an increase in vascular resistance and development of endothelial dysfunction [23,24,25].

\section{Conclusion}

The existing literature indicates that in preeclampsia, there is a possibility of vasospasm which may result in the destruction of RBC's leading to anemia and raised serum iron levels. Excess iron reacts with free radicals of cell membrane and lipoproteins initiating lipid peroxidation. This causes a change in the serum activities of ferretin, transferrin, ceruloplasmin and TIBC which may be responsible for hepatic dysfunction, increased vascular resistance and endothelial dysfunction. Therefore early identification of preeclampsia associated with genetic predisposition, physiological and other associated contributing factors will help in better management and reduction in the morbidity and mortality to mother and fetus.

\section{References}

[1] Margaret PR, Johj B, Robert WE, Christopher WG. Redman, Laurence JK. Abnormal iron parameters in the pregnancy 
syndrome preeclampsia. American Journal of Obstetrics and Gynaecology. 2002; 187: 412-418.

[2] Sabitha, Kandi, et al. "Role of Antioxidant Enzymes in Glucose and Lipid Metabolism in Association with Obesityand Type 2 Diabetes." American Journal of Medical Sciences and Medicine 2.1 (2014): 21-24.

[3] Trefor F, Ernest B and Basil TD. Hemoglobin, Iron and Bilirubin. In: Tietz textbook of clinical chemistry and molecular diagnostics. Edited by CA Burtis, ER Ashwood, DE Burns. 4Th edition; $1192-$ 1198.

[4] D C Sharma, Rati Mathur, PP singh. Iron metabolism: A Review. Indian Journal Of Clinical Biochemistry. 1993; 8(2); 80-101.

[5] Prakash M. Role of non - transferrin - bound iron in chronic renal failure and other disease conditions. Indian Journal Of Nephrology. 2007; 17(4): 188-193.

[6] Crichton RR, Charloteaux - Wauters M. Iron transport and storage. European Journal of Biochemistry, 1987; 164(3); 485-506.

[7] Aisen P, Leibman A, Zweier J. Stoichiometric and site characteristics of the binding of iron to human transferrin. Journal of Biological Chemistry. 1978; 253(6):1930-1937.

[8] Granier T, Langlois d' Estaintot B, Gallois B, Chevalier JM, Precigoux $G$ et al.,. Structural description of the active sites of mouse $\mathrm{L}$ - chain Ferritin at 1.2 A resolution. Journal of Biological Inorganic chemistry. 2003; 8(1-2); 105-111.

[9] Burtis CA, Ashwood ER, Bruns DE. Peptides and protein. Tietz textbook of clinical chemistry and molecular diagnostics. 2006; 556-557.

[10] Philippe A, Gianazza E and Mischel L. Study of acute phase reactants ceruloplasmin. Methods in enzymology. 1998; 163: 441452.

[11] Pamela Bielli, Lilia Calabrese. Structure to function relationships in ceruloplasmin: a 'moon lighting protein. Cellular and Molecular Life sciences. 2002; 59: 1413-1427.

[12] Mohanty S, Nayak N, Nanda N, Rao P. Serum lipids and malondialdehyde levels in primiparous patients with pregnancy induced hypertension. Indian Journal of Clinical Biochemistry. 2006; 21(1): 189-192.

[13] Dr. Tasneem Zafar, Dr. Zafar Iqbal. Iron status in pre eclampsia. Journal of professional Medicine. 2008; 15(1): 74-80.

[14] P. Samuels, EK Main, MT Mennuti, SG Gabbe. The origin of serum iron in pregnancy induced hypertension.American Journal of Obstetrics and Gynaecology. 1987; 157: 721-725.
[15] N. Vitoratos, E. Salamalekis, N Dalamaga, D Kassanos, G Creatsas. Defective antioxidant mechanisms via changes in serum ceruloplasmin and total iron binding capacty of serum in women with pre eclampsia. European Journal of Obstetrics and Gynaecology \& Reproductive Biology. 1999; 84(1): 63-67.

[16] Hubel CA, Boberts JM, Tayler RN. Lipid peroxidation in pre eclampsia; a new prospectives on pre eclampsia. American journal of Obstetrics and Gynaecology. 1989; 161: 1025-1034.

[17] Rabadeh T, Parya BF. Relation between S. Ferritin and iron parameters with preeclampsia. Journal of Family and Reproductive Health. 2007; 1(2): 87-91.

[18] Ganiyu A, Ayo A, Ayodele B, Adijat A, Adebayo A. Serum concentrations of imunoglobulins and acute phase proteins in Nigerian women with preecampsia. Reproductive Biology 2006; 6(3): $265-274$

[19] CA Hubel, AV Kozlov, VE Kagan. Decreased transferrin and increased transferrin saturation in sera of women with preeclampsia: Implications for oxidative stress. American Journal of Obstetrics Gynaecology. 1996; 175: 692-700.

[20] P. Samuels, EK Main, MT Mennuti, SG Gabbe. The origin of serum iron in pregnancy induced hypertension. American Journal of Obstetrics Gynecology. 1987; 157: 721-725.

[21] Hubel CA. Dyslipidemia, iron and oxidative stress in preeclampsia: assessment of maternal and feto-placental interactions. Seminar Reproduction Endocrinology. 1998; 16: 75-92.

[22] CA Hubel, Lm Bodnar, G Harger, RB Ness, JM Roberts. Nonglycosylated ferritin predominates in the circulation of women with preeclampsia but nor intrauterine growth restriction. Clinical Chemistry. 2004;50(5): 948-951.

[23] L - Shakour - Shahabi, S. Abbasali - Zadeh and N. Rashtchi zadeh. Serum level and antioxidant activity of ceruloplasmin in preeclampsia. Pakistan Journal of Biological science. 2010; 13(13) 621-627.

[24] Titantin K, Tamar S, Rusudan K. Alterations of oxidative metabolism at the pregnancy attended with preeclampsia. Tbilisi State Medical Unversity. 2004; 4(1): 34-36.

[25] Shalini Gupta, Smiti Nanda, Uma Singh, Sadhana Bansal and Harbans Lal. Evaluation of the changes in serum iron levels in preeclampsia. Indian Journal of Clinical Biochemistry. 1997; 12(1): 91-94. 